\title{
Finding satisfaction: intrinsic motivation for synchronous and asynchronous communication in the online language learning context
}

\author{
Daniel Bailey ${ }^{1} \cdot$ Norah Almusharraf $^{2}$ (D) Ryan Hatcher $^{3}$
}

Received: 17 September 2020 / Accepted: 23 October 2020/ Published online: 5 November 2020

(C) Springer Science+Business Media, LLC, part of Springer Nature 2020

\begin{abstract}
Intrinsic value is related to intrinsic motivation and influences learners' decisions to begin, continue, and return to learning tasks. In the context of a fully online foreign language English course, we used structural equation modeling to explore the motivation for asynchronous collaborative writing practice, motivation for video-synchronous speaking practice, course satisfaction, and the mediating effect course satisfaction has on behavioral intentions to use language learning technology. Cross-sectional survey results $(n=186)$ revealed that students who were motivated by asynchronous online collaborative writing were more likely to enjoy online learning in general when compared to students who reported motivation for video-synchronous online speaking practice. Moreover, the relationship between motivation for collaborative writing and behavioral intentions to use language learning technology was mediated by course satisfaction. A follow-up open-ended survey $(n=65)$ revealed that students held positive views for online second language writing and speaking practice overall but for distinctly different reasons. The findings are discussed in terms of their theoretical implications for modeling e-learning approaches with significance for promoting instructional training effectiveness and transformative learning.
\end{abstract}

Keywords Intrinsic value - Intrinsic motivation · Online learning · EFL learning · Online writing $\cdot$ And speaking activities

\footnotetext{
Norah Almusharraf

nmusharraf@psu.edu.sa

Daniel Bailey

dbailey0566@kku.ac.kr

Ryan Hatcher

rjhatcher@gm.hannam.ac.kr
}

Extended author information available on the last page of the article 


\section{Introduction}

Due to the COVID-19 pandemic, universities across the world were forced to shut down. South Korea experienced one of the earliest outbreaks preventing any offline courses from being held and pushing the majority of communication courses online (Bahk 2020). Students attending English courses participated through video conferencing platforms, which was a new channel of computer-mediated communication (CMC) for instructors and students. Prior to the COVID-19 pandemic, blended and flipped learning courses were carried out through course learning management systems (LMS), if at all, and communication was often asynchronous, either through email, online discussion boards, or direct messages. However, under the shadow of COVID-19, the proportion of students highly satisfied with their experience in courses fell from $51 \%$ pre-COVID to $19 \%$ post-COVID ( $n=1000$; Lederman 2020).

Discussion forums have been used extensively in blended and fully online courses for decades (Saeed and Ghazali 2017). Online discussion forums are popular interactive tools used for educational purposes (Payne 2020). An advantage of online discussion forums is that text-based communication allows time for reflection, critical thinking, and self-awareness (Saeed and Ghazali 2017). Moreover, with online discussion forums, a community of learners produces and continually improves on their ideas, which allows knowledge construction to become a social activity. Within forum threads, active participants are constantly contributing content, negotiating meaning, creating output, and observing input.

The video-synchronous speaking practice provided technology-enhanced communication options to schools when COVID-19 forced offline classes to be canceled (Rapanta et al. 2020). Videoconferencing combines oral and body language with a variety of other modalities (e.g., text-chat, pictures, and videos), which afford students additional options on how to communicate with one another while resembling speaking practice that occurs in the English as a second or foreign language (ESL/EFL) classroom.

Through the implementation of videoconferencing tools and activities, students' perceived course satisfaction becomes critical for promoting productive formal and informal interactions (Zimmerman 2002). Course satisfaction is associated with higher academic outcomes (Doménech-Betoret et al. 2017), plays a significant role in increasing motivation (Nortvig et al. 2018), and influences behavioral intentions to help learners meet academic goals (Shahijan et al. 2016).

Generally, online education studies tend to focus on online teaching effectiveness or tend to compare an online course to its offline counterpart (Shire et al. 2020). Further, studies in offline education often center on course expectations (Mupinga et al. 2006), learning expectations (Luyten and Bazo 2019), and course satisfaction (Garnjost and Lawter 2019), but only now amid COVID-19 are we able to explore intrinsic motivation on course satisfaction in a fully online EFL context, and in so doing, contribute to parsimony in extant research on motivation psychology. This study seeks to understand how intrinsic motivation for asynchronous writing and synchronous speaking practice influences student perceptions of course satisfaction, and consequently, behavioral intention to use language learning technology. To this end, the following research questions were asked:

Research Question 1: What is the effect of intrinsic motivation for collaborative writing practice on online course satisfaction? 
Research Question 2: What is the effect of intrinsic motivation for videosynchronous speaking practice on online EFL course satisfaction?

Research Question 3: What are the direct and indirect effects of online EFL course satisfaction on the behavioral intention to use language learning technology?

Research Question 4: How do students describe intrinsic motivation for speaking and writing practice in an online EFL course?

\section{Literature review}

\subsection{Theoretical framework}

This study incorporates constructs from the subjective task value component of Eccle's expectancy-value theory and the intrinsic motivation component of Deci and Ryan's (1985) self-determination theory. According to Eccles' $(1983,2005)$ characterization of subjective task value, positive and negative values are related and perceived within academic and professional choices. Predominantly, task value reveals individuals' choice of whether or not they want to participate in a task and why. The concept of task value is grounded in educational psychology and has practical applications in determining learners' participation, choice of task, and task performance (Wigfield and Cambria 2010). In Eccles et al.'s (1998) model of achievement-related choices, most analysis of individual actions is centered on how expectations and values related to performance, choice of different tasks, and emotions are negotiated.

A closer look at the literature on subjective task value in education reveals several gaps and shortcomings, mainly in research areas where adult learners' task values are linked to their motivation and enjoyment to be engaged in ongoing learning. Eccles' expectancy-value theory (Wigfield and Eccles 2000) provides a methodological approach suited within a sociocultural context for experiential examinations of motivation. Thus, the tenets from the self-determination theory by Ryan and Deci (2000) have connections and complements with the value components of expectancy-value theory. In specific, self-determination theory is an inclusive framework for understanding dynamics that aid or challenge intrinsic motivation, self-directed extrinsic motivation, and psychological wellness, all issues of direct applicability to educational settings (Ryan and Deci 2020). Self-determination theory is associated with individual motivation and personality in social contexts that distinguish motivation in terms of being selfdirected and controlled (Deci and Ryan 1985; Ryan and Deci 2000). Components of self-determination theory were utilized to guide and interpret research on many new topics, including motivation. Ryan and Deci (2000) clarify self-determination theory and its facilitation of intrinsic motivation. Individuals can take the initiative to be engaged or alienated within social environments, and these factors are guided by intrinsic motivation components of self-determination theory that facilitate or prevent the natural processes of self-motivation learning development (Deci and Ryan 1985; Ryan and Deci 2000).

Moreover, intrinsic value is directly related to intrinsic motivation and influences learners' decisions to initiate, carry on, and return to learning tasks. For example, when learners feel satisfied, they yield improved self-motivation. Intrinsic value is the motivation that uplifts learners' interest in the tasks offered to them. Once they get 
motivated to accomplish an activity or a task, they would ultimately exert their full determination, time, and energy to continue learning (Deci and Ryan 2008; Deci and Ryan 2012). Intrinsic motivation is the natural, inherent drive to seek out challenges and new possibilities that self-determination theory associates with cognitive and social development.

\subsection{Video-synchronous speaking practice}

There exists a considerable body of literature on utilizing a range of multimedia technologies in developing second language (L2) oral proficiency with specific emphasis on synchronous computer-mediated communication CMC. Huffman (2010) argues that adequate and appropriate employment for mobile technologies in synchronous CMC environments would facilitate meaningful and successful language learning and empower learning environments to surpass the classroom's physical boundaries. Payne and Whitney (2002) employed a quasi-experimental research design with the control group meeting four times a week face-to-face and the experimental group meeting two times a week face-to-face and two times in a class chatroom. Both groups showed improvement in language proficiency; however, only gains in the experimental group were significant, which was attributed to the comprehensible output available with CMC (Payne and Whitney 2002, p. 24). Engaging in synchronous $\mathrm{CMC}$ helped students practice pronunciation through subvocalization. Students practiced general language proficiency through noticeable output (e.g., modeling) and external feedback (e.g., clarification requests). Kato et al. (2016) compared an experimental group of language learners attending offline English classes and video-synchronous CMC classes to a control group attending only offline English classes. One hour of videoconference practice each week for 15 weeks improved speech rates while speech rates decreased for students in offlineonly conditions. Moreover, the mean length of utterances for the experimental group showed significant increases, while no changes were noticed in the control group, showing videosynchronous mediated communication supported offline L2 speaking practice. In another collaborative study, Chen (2019) investigated the influence of technology-mediated task-based language teaching on L2 speaking abilities. Results revealed through asynchronous online English-speaking activities (i.e., video recording productions and publications), students enjoyed making videos and reported increases in their English-speaking abilities.

\subsection{Online collaborative writing}

Research exploring the online collaborative writing in the EFL context is well represented in the literature (Bikowski and Vithanage 2016; Yanguas 2020; Yeh et al. 2011). Bikowski and Vithanage (2016) examined the influences of recurrent in-class online collaborative writing on individual writing scores using Google Docs. The findings showed that collaborative web-based participants experienced higher scores than individual web-based writing participants. Along the same lines, Elola and Oskoz (2010) explored the implication of discussion boards, wikis, and chats in two L2 Spanish courses. These online writing tools promote collaboration and produce content and linguistic improvement (Bikowski and Vithanage 2016). 
Within Yeh et al.'s (2011) study, a system called Process-Writing Wizard was provided as a real-time process-oriented collaborative writing practice for EFL learners to scaffold in a synchronous online chat room. Within these collaborative writing settings, learners were asked to create team agendas, outlines, and articles. The result of the examination of students' collaborative interactions revealed that the students had positive attitudes toward the operating system, and they were motivated to use the system in future writing tasks. Further, students writing outcomes showed that students performed better outcomes in content quality and organization with the aid of the system. Bhowmik et al. (2019) also reported benefits of students' collaboration, including raising critical awareness about language practice in academic writing, which led to an enhanced understanding of the meaning-making processes in text construction.

Collaborative writing is not without shortcomings despite learning contributions. Bhowmik et al. (2019) explain challenges identified within a Canadian post-secondary context includes learners' unfamiliarity with peer collaboration, absence of clear guidelines regarding the steps to be followed, inadequate proficiency levels within groups, and group members' different experiences, which can cause struggle in communication among partners. A qualitative study by Such (2019) investigated how post-secondary EFL learners work collaboratively to complete online writing assignments using wikis. The results showed that linguistic and directional scaffolding and a grading rubric helped learners in meaning-negation but caused challenges with participation and collaboration, especially on spelling and grammar usages.

\subsection{Online course satisfaction}

Pozón-López et al. (2020) examined the participants' satisfaction and intention to use online courses in the future. Pozón-López et al.'s (2020) behavioral model analysis confirmed the strong relationship between participants' satisfaction and autonomous motivation with their technology use. The findings also reveal that perceived satisfaction is influenced by the course's quality, its production value, and its effectiveness. Their findings are aligned with Song et al. (2017) argument that the perceived usefulness and ease of a type of technology determine behavioral intention towards using it.

For the most part, online collaborative writing and video-synchronous mediated L2 communication research have been mutually exclusive (Kato et al. 2016; Saeed and Ghazali 2017; Such 2019), leaving a gap in our understanding of how students attribute sources of intrinsic motivation for different types of learning activities, and a divide in how we view approaching their instruction. Research on student satisfaction in the online learning context has been inconclusive; therefore, this study aims to explain the origins of intrinsic motivation and its path to online course satisfaction and continuing engagement with language learning technology.

\section{Methods}

A quantitative approach was first taken using a cross-sectional survey design to investigate the relationships among intrinsic motivation, course satisfaction, and behavioral intentions. In educational research, a cross-sectional study is a type of observational study that analyzes data from a representative subset of a population at a 
specific point in time. Secondly, an open-ended survey was used to capture the participants' voices concerning intrinsic motivation beliefs about their writing and speaking practice in the online EFL course. Using thematic analysis, a top-down process for coding was carried out following procedures set forth by Stewart et al. (2015), which began with two researchers implementing an independent study of data followed by a second collaborative review of identified themes. The EFL course was an ideal learning environment for the nature of this study because writing and speaking communication skills are a core component of EFL classes. Similarly, writing and speaking practice are essential for disciplines related to first language (L1) classes, including English, Speech, Communication, Academic Writing, and even Psychology.

\subsection{Participants}

Six English communication skills courses consisting of $186($ Male $=88$, Female $=98)$ freshman $(n=127)$ and sophomore $(n=59)$ students taught by the same instructor from a South Korean university completed the initial survey after ten weeks of participating in EFL videoconference courses. To triangulate findings, three classes $(n=65)$ were randomly selected to complete an open-ended follow-up survey six weeks after the initial survey.

\subsection{Learning environment}

The 120-min weekly classes met once a week to practice speaking, writing, listening, and reading. The activity book Smart Choice 2 (Wilson 2016) was used during the semester to provide online speaking practice activities and deliver topics for online writing practice. Smart Choice 2 consists of 12 units covering topics related to entertainment, hobbies, family, and technology. The instructor would begin class with engagement activities followed by vocabulary practice through role-play and grammar exercises (20 to $30 \mathrm{~min}$ ). The remainder of the class was dedicated to partner speaking activities in zoom breakout rooms (50-60 $\mathrm{min}$ ) followed by brainstorming activities to develop content for writing assignments (20-30 min). Students would begin online writing practice during class time and continue the writing practice as homework.

\subsubsection{Online writing practice with LMS discussion forums}

All courses were taught online with asynchronous collaborative writing through the course LMS and video-synchronous speaking practice through the videoconference platform Zoom. The online discussion forum is an electronic network facilitating active communication among students who create threads and reply to one another through comments. Fig. 1 displays an example of an LMS writing activity that asked students to introduce themselves to the class. Other types of LMS discussion forum activities asked students to describe an interesting photo, describe plans, or compare two types of technology. Students would then comment on each other's discussion thread, creating a written dialogue.

\subsubsection{Video-synchronous speaking practice}

The Zoom videoconference platform was used for online speaking practice. Videoconferencing entails using a telephone with a video display for online group meetings 



Fig. 1 Example Forum Activity

rather than individual or face-to-face meetings. Video-synchronous mediated L2 communication is conceptually different from asynchronous, entirely online, or blended classes because students are expected to participate with one another and the instructor in real-time. The instructor chose Zoom for convenience and the option to parse students into separate videoconference rooms. Separate concurrent sessions (i.e., Zoom breakout rooms) is a feature that allows students to privately talk with each other, screen-share, and share files.

Figure 2 illustrates the zoom display for a student presentation. In addition to Zoom presentations, other online speaking activities included reading aloud practice, repeating target phrases, storytelling, hosting group discussions, and holding class debates.

\subsection{The instrument}

Table 1 displays the items composing the instrument. The four items used to generate intrinsic motivation levels for collaborative writing practice were taken from the Intrinsic Motivation Inventory (IMI; Ryan 1982). The IMI is a 30 item self-report, Likert-type rating scale measuring motivational structures for targeted activities in sports, education, and medical procedures (Ryan 1982). The original item from the IMI scale is, "I enjoyed doing [this activity] very much." while the modified version reads, "For my online English class this semester, I enjoy sharing my writing with my classmates through discussion forum activities." The second item was taken from the IMI's usefulness/value scale and reads, "I think that doing [this activity] is useful," while the modified version reads, "For my online English class this semester, I think

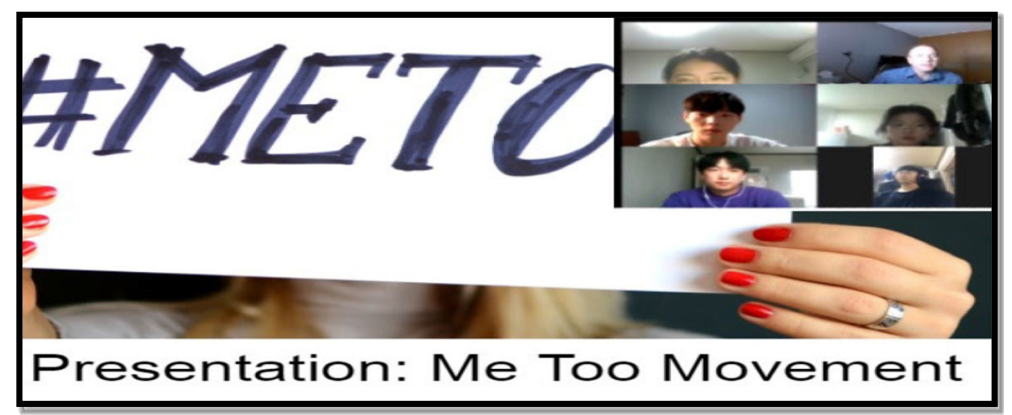

Fig. 2 Example Videosynchronous Speaking Activity 
Table 1 Survey Items

Course Satisfaction

1 I am satisfied with my online English class this semester.

2 I feel satisfied with attending my online English class this semester.

Intrinsic Motivation for Online Writing Practice

3 In my online English class this semester, I enjoy sharing my writing with my classmates through discussion forum activities

4 In my online English classes this semester, I enjoy practicing my writing through discussion forum activities,

5 In my online English class this semester, I think that practicing English with discussion forums is a useful way to study English.

6 In my online English class this semester, I enjoy sharing my writing with my classmates through discussion forum activities.

Intrinsic Motivation for Video-Synchronous Speaking Practice

7 In my online English class this semester, I enjoy practicing speaking through videoconference activities.

8 In my online English class this semester, I enjoy having conversations with classmates during our videoconference activities.

9 In our online English class this semester, practicing English conversation through videoconferencing is a useful way to study English.

10 In online English class this semester, I enjoy doing partner speaking activities in our video conference class

Behavioral Intention to use Language Learning Technology

11 I will use language learning tools often when studying English

12 I will use language learning tools frequently in the future

that practicing English with discussion forums is a useful way to study English." Behavioral intention to use e-learning tools was measured using two items from the technology acceptance model (Davis et al. 1989).

\subsubsection{Follow-up survey}

An in-house developed open-ended survey measured student perceptions of their online writing and video-synchronous speaking practice experiences. Explanation and administering of the survey were in the student's first language, and students were instructed that they could respond in either Korean or English. There were four concepts taken from Ryan's (1982) Intrinsic Motivation Inventory, which included value, reward, usefulness, and enjoyment. Students were asked to rate [strongly disagree, 1 to strongly agree, 7] how much they believed a term described their experience with their online EFL class. Next, they were asked to justify that rating, first in terms of their online writing practice and again in terms of their online speaking practice. Students had to explain their experience and/or perceptions twice for each concept, once in the context of online writing practice and once in the context of video-synchronous speaking practice.

Items from both surveys were first written in English and then translated to Korean by a translation specialist. A second translation specialist then checked the Korean 
translation. Awkward wording or discrepancies in meaning were discussed between translators and resolved.

\subsection{Data analysis}

Quantitative data analysis was carried out using the statistical software packages IBMSPSS-AMOS 25.0. Initially, descriptive statistics were performed to learn mean scores, a Pearson correlation of the study variables. Linear regression was then used to generate Mahalanobis and Cook's distance values to look for outliers in which four existed and were removed, leaving 186 total respondents. Normal distributions were observed for the indicators of the latent factors concerning kurtosis and skewness. No kurtosis value was outside the range of -1 to +1 , indicating acceptable levels of normal univariate distribution (George and Mallery 2010). First, exploratory factor analysis with SPSS followed by confirmatory factor analysis (CFA) with AMOS was used to validate the latent constructs. Once validated, variables were placed into the structural model to execute the SEM procedure.

The top-down approach involved students writing about their online writing and speaking experience and perceptions regarding value, reward, usefulness, and enjoyment. For the first step in coding, two independent researchers followed deductive reasoning to identify conceptually unique sources of motivation for writing and speaking practice. Specifically, phrases that attributed learning outcomes or engagement were marked and categorizes. In the second step, the researchers reviewed their independently derived categories and revised codes accordingly. A cluster analysis was generated using the qualitative data analysis software NVivo (version 12; QSR International 1999). Cluster analysis is an exploratory technique used to visualize patterns by grouping sources or nodes that share similar words.

\section{Results}

Table 2 presents results from Pearson correlation and mean score analyses of the study variables. Course satisfaction and intrinsic value for speaking had moderate mean scores, while the intrinsic value for writing was relatively lower, with a mean score value of 2.64 ( $\mathrm{SD}=0.91)$. Pearson correlation revealed statistically significant relationships across all variables with small to large effect sizes (Cohen 1988). Intrinsic motivation for writing and intrinsic motivation for speaking, and intrinsic motivation for writing and course satisfaction had large effect sizes with correlation values, $r>.50$ $(p<.001)$. Medium effect sizes were found for the relationships between behavioral intentions to use language learning technology and intrinsic motivation for writing practice, behavioral intentions and intrinsic motivation for speaking, and again for behavioral intentions and course satisfaction, $r=.30$ to $.50(p<.001)$.

Before calculating the structural model, the study needed to validate the latent constructs for unidimensionality, validity, and reliability. Initially, a four-factor correlated model was used to validate the four variables of interest (i.e., intrinsic motivation for speaking practice, intrinsic motivation for writing practice, course satisfaction, and behavioral intention to use language learning technology). Factors for the components were extracted through the maximum-likelihood method with Varimax rotation. 
Table 2 Pearson Correlation and Mean Score Results for Study Variables

\begin{tabular}{llllll}
\hline & 1 & 2 & 3 & 4 \\
\hline 1 & IM for Writing & & & & \\
2 & IM for Speaking & $.543^{* *}$ & & & \\
3 & Course Satisfaction & $.530^{* *}$ & $.291^{* *}$ & & \\
4 & Behavioral Intentions & $.469^{* *}$ & $.387^{* *}$ & $.450^{* *}$ & \\
& Mean & 2.56 & 2.88 & 3.059 & 3.16 \\
& SD & 0.83 & 0.765 & 1.013 & 0.69 \\
& Skewness & .354 & -.224 & -.250 & -1.24 \\
& Kurtosis & .491 & .671 & -.312 & -.323 \\
\hline
\end{tabular}

Note: ${ }^{* *}=\mathrm{p}<.001$; IM for writing, intrinsic motivation for writing; IM for speaking, intrinsic motivation for speaking

Unidimensionality was achieved as the factor loading for all items was above .50. Several established criteria for factor analysis were used. The Kaiser-Meyer-Olkin Measure of sampling adequacy was $.803(p<.001)$, above the recommended value of .6, and Bartlett's Test of Sphericity was significant $\left(c^{2}(66)=1837.19, p<.001\right)$ and the Cronbach's alpha values reached the minimum value of 0.7 (Fornell and Larcker 1981). Composite reliability, average variance extracted, and Cronbach alpha's values were calculated to address the convergent validity measures (Table 3 ).

Convergent validity was achieved as all AVE values were at or above the recommended value of .50 (Hair et al. 2010). The initial data computation also revealed that the data demonstrated homogeneity of variance and met linearity assumptions, indicating requirements for CFA were satisfied.

The study proceeded to measure the model validity using CFA, a standard statistical technique for testing a theoretical model (Kline 2011). The results of the first round of CFA $\left(X^{2}=177.906 ; d f=59 ; p<.001 ; \mathrm{CMIN} / d f=3.015 ; \mathrm{RMSEA}=.104 ; \mathrm{NFI}=.846\right.$; $\mathrm{CFI}=.889 ; \mathrm{IFI}=.900 ;$ PCLOSE $=.000)$ suggested that the model fit indices were insufficient. Upon checking modification indices, it was recommended that items 3 and 4 on the intrinsic motivation (IM) for speaking practice scale (M.I. $=60.98$ ) and items 3 and 4 on the IM for writing practice (M.I. = 15.13) covary. RMSEA decreased from .104 to .049 . Adequate model fit was achieved after running the model again $\left(X^{2}=82.287 ; d f=57 ; p<.016 ; \mathrm{CMIN} / d f=1.44 ; \mathrm{RMSEA}=.038 ; \mathrm{NFI}=.929 ;\right.$ $\mathrm{CFI}=.976 ; \mathrm{IFI}=.977 ;$ PCLOSE $=.507)$, indicating that construct validity was achieved. IM for speaking practice, IM for writing practice, online EFL course

Table 3 Model Validly and Cronbach's Alphas Extracted

\begin{tabular}{lllllll}
\hline & & CR & AVE & MSV & ASV & Cron $\alpha$ \\
\hline 1 & IM for Speaking & .767 & .50 & 0.295 & 0.176 & .761 \\
2 & IM for Writing & .868 & .57 & 0.295 & 0.265 & .867 \\
3 & Course Satisfaction & .868 & .77 & 0.281 & 0.189 & .858 \\
4 & Behavioral Intentions & .769 & .63 & 0.220 & 0.191 & .762 \\
\hline
\end{tabular}


satisfaction, and intention for future use of educational technology for L2 language practice were conceptually unique.

Path coefficients are seen in Fig. 3. The structural model explains $32 \%$ of the variance in expected course satisfaction and $30 \%$ of the variance in the behavioral intention to use language learning technology. The next step in answering the research questions was to investigate the path coefficients among the study's variables and the mediating effect of course satisfaction between the independent variables and behavioral intention to use language learning technology.

\subsection{Research questions one and two}

For research question one, the final model shows a statistically significant positive path coefficient from the intrinsic motivation for writing practice to course satisfaction, indicating that increased IM levels for writing practice result in increasing levels of online EFL course satisfaction. For research question two, the relationship between IM for speaking practice and EFL course satisfaction disappears when added to the model. The relationships with video-synchronous speaking practice observed earlier with the Pearson correlation disappeared when added to the model.

\subsection{Research question three}

Research question three explored the direct and indirect effects course satisfaction has on the behavioral intention to use language learning technology. A standardized path coefficient of .291 ( $p=.005)$ was observed after running the model, indicating that increased levels of satisfaction predicted behavioral intentions. The second part of the research question three goes on to identify mediation effects by course satisfaction. A 5000 -sample bootstrap was run to identify indirect effects due to the model's inclusion of course satisfaction. The indirect effect for IM for online writing practice was $.59 \mathrm{x}$ .29 equaling $.171(p<.001)$. The direct path was reduced from $.34(p<.001)$ to .18 $(p=.183)$, indicating full mediation by course satisfaction. Mediation analysis was not carried out for IM for speaking practice because of the insignificant path between IM

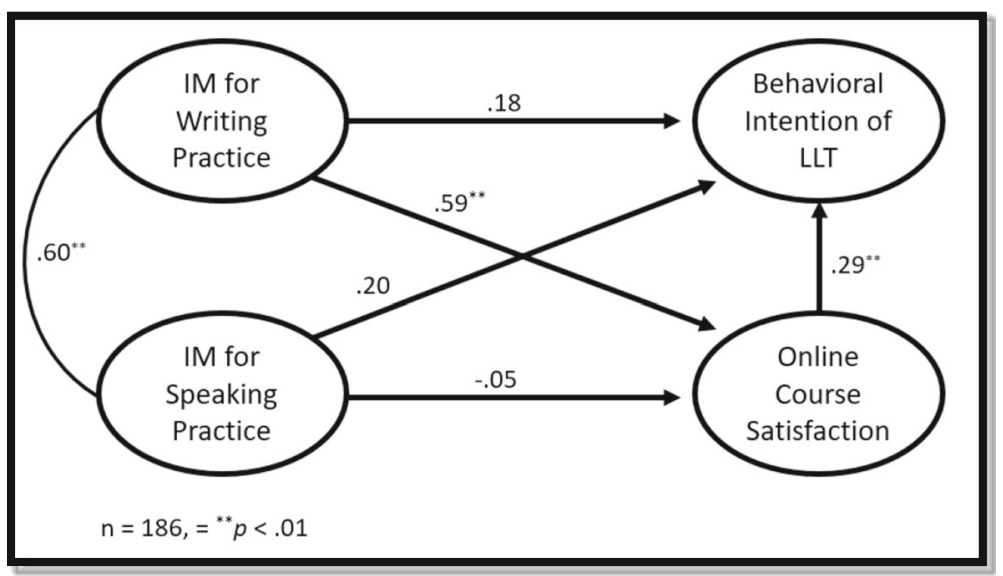

Fig. 3 Study Model with Coefficient Paths and Squared Multiple Correlations 
for speaking and course satisfaction (path a) before the inclusion of course satisfaction (path c'), a prerequisite for mediation to occur (Baron and Kenny 1986). Table 3 shows the structural model's direct and indirect effects (bootstrap sample, $n=5000$ ) (Tables 4 and 5).

Findings from research questions one to three indicate that increasing intrinsic motivation levels for collaborative writing predict online EFL course satisfaction, and this path also partly explains behavioral intention to use language learning technology.

\subsection{Research question four}

Research question four explores similarities and differences in student reported perceptions of video-synchronous speaking practice and collaborative writing practice in the context of a fully online EFL course. A follow-up survey administered to 65 students collected information about their online course experience in regard to enjoyment, value, usefulness, and reward. In all, eight open-ended responses by 65 students produced approximately 520 responses.

Initially, two independent analyses of responses were carried out to identify common themes in which 12 emerged. Next, responses were coded according to the identified themes resulting in the cluster analysis illustrated in Fig. 4. The NVivo 12 cluster coding similarity approach allows the clustered data to be analyzed in terms of similar words based on Pearson's correlation coefficient values. The result was a horizontal diagram that shows similar codes on the same branch and dissimilar codes on different branches.

The students attributed increasing levels of intrinsic motivation for SVMC to Having Opportunity to Practice English (e.g., I don't usually have a chance to speak in English, but I think I gained some confidence because I can speak in English), Developing Pronunciation Skills (e.g., my English pronunciation has improved a lot), Developing Conversation Skills (e.g., It [SVMC] improves my English conversation skills), Communicating with Classmates (e.g., it was [a] good experience talking with friends), and Communicating with the Instructor (e.g., I am happy the professor tried hard to communicate with us). Having Opportunity to Practice English and Increasing Confidence with English branched closest together in responses about speaking practice, which was due to the use of terms related to pronunciation, fluency, and improvement.

Table 4 Direct Effects of Regression Weight Estimates

\begin{tabular}{llllll}
\hline Direct Path & $\beta$ & S.R & C.R & Beta & $p$ \\
\hline IMW $\rightarrow$ BI & .183 & .198 & 1.332 & .180 & .183 \\
$\mathrm{IMW} \rightarrow$ CS & .856 & .198 & 4.311 & .593 & $.000^{\text {*** }}$ \\
$\mathrm{CS} \rightarrow$ BI & .205 & .074 & 2.787 & .291 & $.000^{* *}$ \\
$\mathrm{IMS} \rightarrow$ BI & .224 & .194 & 4.311 & .201 & $.000^{* * *}$ \\
$\mathrm{IMS} \rightarrow \mathrm{CS}$ & -.085 & .171 & -.493 & -.054 & .622 \\
$\mathrm{CS} \rightarrow$ BI & .205 & .074 & 2.787 & .291 & $.005^{* *}$ \\
\hline
\end{tabular}

Note: ${ }^{* *}=p<.001$; Intrinsic motivation for writing practice, IMW; Intrinsic motivation for speaking practice, IMS; Behavioral Intention for LLT, BI, Course Satisfaction, CS 
Table 5 Indirect Effects of Regression Weight Estimates

\begin{tabular}{llcc}
\hline Direct Path & $\beta$ & Beta & $p$ \\
\hline IMW X CS X BI & .175 & .173 & $.01^{*}$ \\
\hline
\end{tabular}

Note: ${ }^{*}=p<.01$

Communicate with Classmates and Communicate with the Instructor branched further away from other themes in the speaking category because of references to terms that described interactions with others (e.g., with a partner, with the instructor, communicate with, and my friends). Students also reported enjoying the opportunity to develop relationships with their classmates through the zoom speaking activities, represented through responses like, "I was able to make friends with my classmates easily," and "I was able to talk about many things."

The students reported increasing levels of intrinsic motivation for writing practice to themes such as Learning New Vocabulary (e.g., I got to know words that I didn't know), Having English Writing Opportunity (e.g., The class was valuable because I was able to practice my writing skills regularly) and Developing Grammar Skills (e.g., it helped me understand grammar). References to grammar skills were coded separately from writing skills because they mentioned grammar specifically, while responses underwriting skill frequently mentioned writing skills specifically along with references to writing fluency and accuracy.

Most references to the intrinsic motivation terms (e.g., value, reward, usefulness, and enjoyment) in the writing columns were concerning benefits to writing skills in general and grammar and vocabulary gains specifically. Another theme that emerged in openended responses about writing-related to reflection, planning, and meta-cognition. Students made several statements in their open-ended responses around thinking about what and how they wrote.

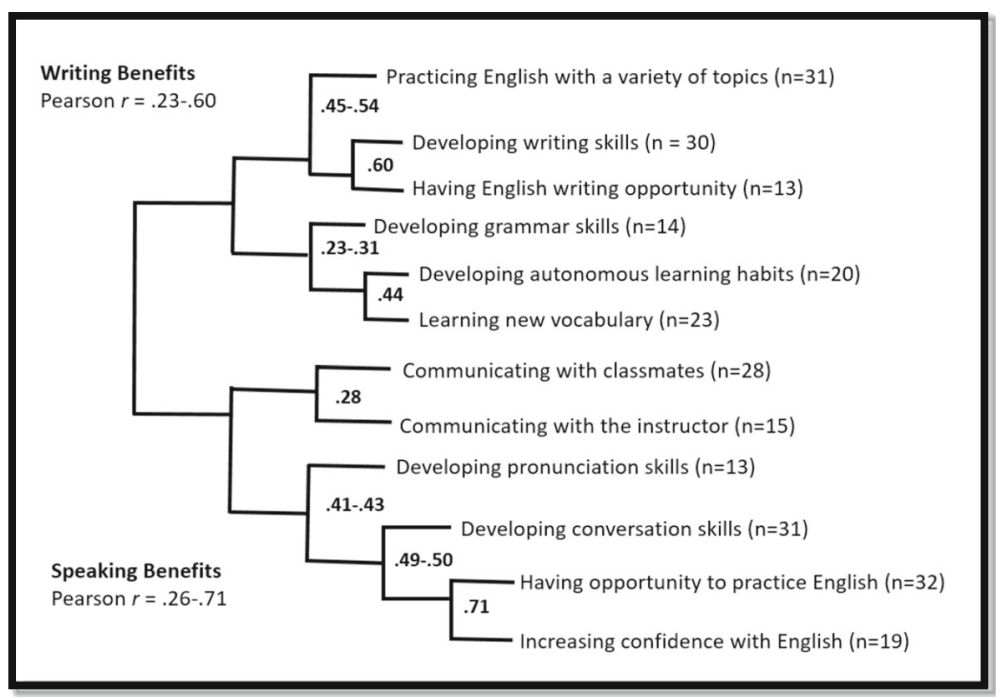

Fig. 4 Cluster Analysis of Open-Ended Responses 
Overall, students used terms that described benefits to language skills, specifically when describing writing practice and language that described benefits to socializing and communication when describing the online speaking practice. Online speaking and writing practice are not mutually exclusive (Spring et al. 2019); however, these findings provide evidence that writing practice directly influences grammar and vocabulary skills, and speaking practice directly influences socialization, communication, and pronunciation. Language knowledge gains to writing skills are linked with course satisfaction, while language gains associated with socializing were not illustrated in the structural equation model (Fig. 3).

\section{Discussion}

This study showed that EFL students who have intrinsic motivation for online writing practice are more likely to be satisfied with an online EFL course compared to students who report having intrinsic motivation for video-synchronous speaking practice. Online EFL course satisfaction completely mediates the relationship between intrinsic motivation for collaborative online writing practice and behavioral intention to use language learning technology. Contrarily, intrinsic motivation for video-synchronous speaking practice showed no relation to EFL course satisfaction or behavioral intentions.

The findings from research question 1: What is the effect of intrinsic motivation for collaborative writing practice on online course satisfaction? determined the influence asynchronous collaborative writing practice has on EFL course satisfaction. Payne (2020) states that some learning activities are more productive online, particularly for learners who are less satisfied performing and making mistakes in front of their peers. Cognitive load is less with asynchronous text discussion, and this was due to the lack of opportunity in video-synchronous mediated communication to go back and review instructions. Specifically, as clarified by Payne (2020), building a weekly progression of activities initiating with the learners with lower cognitive load and developing to those with the higher-cognitive load, for example, instructors could start with an asynchronous writing task with sufficient opportunity for pre-task preparation shadowed by an opportunity for peer feedback and a self-assessment that can prepare them for an authentic synchronous video conference or text chat event. This process and progression of implemented instructional tasks can prepare learners to be comfortable, regardless of time limitations, in a synchronous discussion as they have practiced and collected some vocabulary needed to deliver their perspectives and to practice expressing their thoughts without time pressure.

Findings from research question 2: What is the effect of intrinsic motivation for EFL videosynchronous mediated communication on online EFL course satisfaction? revealed that the relationship between IM for speaking practice and EFL course satisfaction is not clearly connected. From all the four macro English skills, speaking is generally deliberated the most significant and challenging phase of learning a second/ foreign language (Rao 2019). Hopkins (2010) asserts that within synchronous online learning systems, there are many opportunities to facilitate learners to take part in online oral communication with their instructors and their peers and increase their articulated productivity to support collaborative learning (i.e., video and live 
synchronous chats). However, for EFL learners to contribute orally through speaking activities such as delivering presentations, offering explanations, exchanging thoughts, conveying information, making polite gestures and requests, and expressing emotions and opinions, they need to be actively involved in tasks that trigger their motivation and enjoyment (Sanjay and Narayana 2020). Motivation within the speaking activity is described as the responsibility for determining a particular action, the justification of conduct behavior, the endurance with this activity, and the plans of expanded efforts to proceed with this activity (Sanjay and Narayana 2020).

Responses from our students practicing zoom with fellow EFL speakers echo responses from Spring et al. (2019) students who used Skype to practice English between American and Japanese language learners and Chen's (2019) students' reflections regarding their task-based speaking projects. Spring et al. (2019) had students in low and high L2 oral proficiency ranges report "good experiences" (Spring et al. 2019, p. 8) when referring to video-synchronous mediated communication. Chen placed reflection comments into two categories of perceptions (enjoyed the activity) and collaborative (consensus among the group was hard to achieve, and group work was time-consuming).

Further, Spring et al. (2019) study on improvement in oral fluency in the context of video-synchronous $\mathrm{CMC}$ found evidence for factors related to decreased levels of course satisfaction. Experiences and reflections varied significantly between the top and bottom-quartile improvements. Some students commented that their Skype partner did not take the speaking practice seriously. The researchers recognized that at least an intermediate level of oral proficiency is necessary before fully taking advantage of the affordances provided by videoconferencing CMC (Spring et al. 2019).

Findings from research question 3: What are the direct and indirect effects of EFL course satisfaction on the behavioral intention to use language learning technology? cast a new light on the direct and confirmed relationship of course satisfaction and behavioral intention of language learning technology. This result ties well with the findings from Yeh et al.'s (2011) students who reported positive attitudes towards a collaborative writing system to design team agendas and were motivated to use the online writing system in future writing tasks. Furthermore, increasing levels of course satisfaction help explains the relationship between IM for writing practice and behavioral intention for language learning technology. These results support Costley and Lange (2017) findings, who recognized that cognitive load exerted within an online course completely mediates the relationship between instructional design and future behavioral intention to engage in e-learning.

The present study confirmed Eccles's (2005) task value of intrinsic value is directly related to intrinsic motivation and impacts learners' decisions to invest, progress, and return to learning tasks, especially when learners feel satisfied, they show enhanced self-motivation. Intrinsic value is the motivation that elevates learners' responsiveness in the tasks given to them. Once they get motivated to complete an activity or a task, they would eventually employ their full determination, time, and energy to continue learning (Deci and Ryan 2008, 2012). Intrinsic motivation is the standard process to look for challenges and new potentials that self-determination theory associates with cognitive and social growth.

Results from research question 4: What are student perceptions of videosynchronous speaking practice and collaborative writing in the context of an online 
EFL course? Identified student perceptions and mapped similarities and differences between the perceived benefits of video-synchronous speaking practice and collaborative writing. Overall, most students reported being satisfied with their improved writing and speaking skills resulting from the online course. Students enjoyed the added opportunity to practice English, which is not easy in countries like South Korea, where English is not typically spoken outside the classroom.

Language skill gains from writing practice were directly connected to interactions with the LMS content. In learner-content interaction, the content is the subject matter to be learned (Moore and Kearsley 1996) and are either external (e.g., learning new vocabulary or grammar function) or internal (e.g., examining his or her assumptions about subject material). The LMS provided high levels of interactions with asynchronous writing practice among learners at the expense of less cognitive load than video-synchronous speaking practice because students have time to review instructions, organize ideas, and prepare their writing (Payne 2020).

With video-synchronous speaking practice, extraneous cognitive load occurs through unfamiliar instructional design that causes unnecessary processing within the working load, leading to negative learning experiences (Cierniak et al. 2009). Subjective task value tangentially explains negative effects on germane load and negative impact cognitive load has on course satisfaction through the subjective task value subcomponent cost (Eccles 1983). Students may have endured higher costs with videosynchronous speaking practice because of the overly-high effort to understand the target language in real-time.

Gains from speaking practice were most frequently attributed to interactions with others, indicating a disconnect between the course itself and accomplishing the key learning objective of increasing speaking skills. Learner-learner interaction is two-way mutual communication between learners, with or without the presence of an instructor (Moore and Kearsley 1996). Increasing amounts of a learner to learner interaction has a positive effect on student satisfaction, leading to more effective online learning (Jung et al. 2002); however, Thurmond et al. (2002) found that students reported less course satisfaction when learner to learner interaction is compulsory, which may have contributed to the insignificant path relationship between video-synchronous speaking practice and course satisfaction.

\subsection{Pedagogical implications}

These findings generalize to other academic disciplines L1 English (Such 2019), writing (Yeh et al. 2011), communication or speech classes (Spring et al. 2019). The facilitation of intrinsic motivation in learners is seen when they have taken the initiative to be engaged within social environments. Further, some self-regulatory approaches, such as goal setting and self-monitoring, are qualities that teachers can sense by observing their learners' self-awareness of the quality of their work and attentiveness in class. Such self-regulatory approaches are encouraged by the instructors and can lead to progress in students' motivation and achievement (Zimmerman 2002).

Cluster analysis of open-ended responses identified several benefits afforded by video-synchronous speaking practice. Class activities that directly connected these benefits to the course may help students bridge satisfaction in learning 
accomplishments to the course. Instructors can begin by creating opportunities to practice English to help increase L2 confidence. With videoconference platforms like Zoom, this is accomplished through simultaneous breakout room sessions where students practice conversations with one another. Payne (2020) asserts on the significance of the sequencing activities in a weekly development from those with the lower cognitive load to more challenging tasks requiring learners to process and practice the language in authentic context can create enhanced learning outcomes and offer an instructional routine that can be supportive for online learners.

In this study, the online writing course utilized both synchronous tools to enable real-time communication and collaboration and asynchronous tools, which were mainly used as a discussion tool that allowed learners to reflect and participate over a while through a different time or different place. Also, an LMS is ideally designed to facilitate asynchronous communication, file sharing, and class announcements. They support the development, delivery, administration, and assessment of courses in blended or fully online asynchronous learning environments. Videosynchronous mediated communication is integral to EFL instruction but does not have the same historical foundation as research and development in online collaborative writing for academic purposes. Furthermore, Zoom and other video conference platforms are mainly for business meetings and not initially designed for virtual classrooms. This void is quickly filling with an onset of new literature covering videoconference activities that can engage learners and teaching strategies that are aligned with their specific needs. Additional investigation into using Zoom and other learning and teaching platforms is required to determine its effectiveness on student engagement and learning.

\section{Conclusion}

This study investigated the effect of intrinsic value for collaborative online writing, and video-synchronous speaking practice has on online EFL course satisfaction, and consequently, the behavioral intention to use language learning technology. Regarding the benefits and drawbacks of newly available instructional technology tools and implementing some creativity, it is possible to plan learning opportunities that are productive, engaging, and enjoyable for students and teachers. What measures selfregulated and collaborative learning in second language acquisition is not the dependence on socially remote methods of learning but rather the intrinsic initiative, determination, and adoptive skill that allows learners to focus on how they formulate, modify and sustain specific learning practices in social as well as independent contexts (Saeed and Ghazali 2017). Zimmerman 2002). These skills and qualities are critical in our digital era to promote lifelong reflective learners who are motivated to learn.

\subsection{Limitation and future directions}

It is critical to highlight that the results are mainly concerned with the learners' intrinsic motivation in collaborative writing practice and their intrinsic motivation in videosynchronous speaking practice. Therefore, other factors related to age, sociocultural context, and geographic region may produce different results. Further, a more 
comprehensive survey that includes other scales on the intrinsic motivation inventory (Ryan 1982) would provide additional insight into how perceived competence and effort relate to course satisfaction. In addition, this study is limited to one context, which leads to an assessment of one group of students in one semester. Due to the nature of cross-sectional survey research, finding must be considered influenced by responder bias. Further, the potential for measurement error was propagated from excluding any academic outcome variable. A longitudinal study is required to explore the teacher's extents and the learner's satisfaction and application of the employed instructional technology tools and to ensure that online learning tools meet student needs and maintain quality over time. Classroom observations and long-form interviews would be a valuable addition in future studies to capture authentic examination of a specific context in a period. Also, we recommend future studies to utilize multiple robust scales to measure learning constructs related to intrinsic motivation and course satisfaction.

This study suggests that the instructor's effort is vital in promoting and creating online spaces that allow room for creativity and encourage student accountability in tasks trigger motivation. The idiosyncratic nature of learning environments compounded by individual teaching styles prevents any absolute claims that intrinsic motivation for writing practice predicts course satisfaction.

Our results provide a layer of evidence to the assertion that videoconferencing supports learners with heightened levels of intrinsic motivation for writing. Intrinsic motivation for online writing practice supported deeper level learning (e.g., grammar and vocabulary skills) and positively predicted course satisfaction. Contrarily, no such positive relationship between intrinsic motivation for speaking practice and course satisfaction emerged. Accordingly, we call for future research to contradict or confirm our model. While we put forward the argument that course satisfaction is often an antecedent to learning outcomes, this cannot be stated as a truism. Therefore, any future research should consider assessment or some other performance measure. Consequently, this study provides direction for research that explores similarities and differences in relationship building and knowledge acquisition when learning synchronously through video or asynchronously through writing. Moving forward, the growth of e-learning calls for in-depth studies focused on students' motivation and learning satisfaction in alliance with actual learning outcomes. This refining online learning process becomes particularly essential when integrating progress in technology, such as learning analytics and artificial intelligence, continues to open up new possibilities for us to support student learning more efficiently in virtual environments.

Availability of data and materials the data is available for sharing upon request.

Author contributions Daniel Bailey: Method, analysis, and findings.

Norah Mansour Almusharraf: Introduction, literature review, discussion, and conclusion.

Ryan Hatcher: Data collection and data interpretations.

\section{Compliance with ethical standards}

Conflict of interests There is no conflict of interest of a publication. 


\section{References}

Bahk, E, J. (2020). College students unhappy with online lectures. The Korea Times. Retrieved from https:// www.koreatimes.co.kr/www/nation/2020/03/113_285496.html

Baron, R. M., \& Kenny, D. A. (1986). The moderator-mediator variable distinction in social psychological research: Conceptual, strategic, and statistical considerations. Journal of Personality and Social Psychology, 5(6), 1173-1182. https://doi.org/10.1037/0022-3514.51.6.1173.

Bhowmik, S. K., Hilman, B., \& Roy, S. (2019). Peer collaborative writing in the EAP classroom: Insights from a Canadian post-secondary context. TESOL Journal, 10(2), e00393. https://doi.org/10.1002/tesj.393.

Bikowski, D., \& Vithanage, R. (2016). Effects of web-based collaborative writing on individual L2 writing development. Language Learning \& Technology, 20(1), 79-99. http://hdl.handle.net/10125/44447.

Chen, K. T. C. (2019). The effects of technology-mediated TBLT on enhancing the speaking abilities of university students in a collaborative EFL learning environment. Applied Linguistics Review, 1. Advance online publication. https://doi.org/10.1515/applirev-2018-0126.

Cierniak, G., Scheiter, K., \& Gerjets, P. (2009). Explaining the split-attention effect: Is the reduction of extraneous cognitive load accompanied by an increase in germane cognitive load? Computers in Human Behavior, 25(2), 315-324. https://doi.org/10.1016/j.chb.2008.12.020.

Cohen, J. (1988). Statistical power analysis for the behavioral sciences. Hillsdale, NJ: Lawrence Erlbaum.

Costley, J., \& Lange, C. (2017). The mediating effects of germane cognitive load on the relationship between instructional design and students' future behavioral intention. Electronic Journal of e-Learning, 15(2), 174-187 Retrieved from https://eric.ed.gov/?id=EJ1141882.

Davis, F. D., Bagozzi, R. P., \& Warshaw, P. R. (1989). User acceptance of computer technology: A comparison of two theoretical models. Management Science, 35(8), 982-1003. https://doi.org/10.1287/ mnsc.35.8.982.

Deci, E. L., \& Ryan, R. M. (1985). Intrinsic motivation and self-determination in human behaviour. Plenum. https://doi.org/10.1007/978-1-4899-2271-7.

Deci, E. L., \& Ryan, R. M. (2008). Self-determination theory: A macrotheory of human motivation, development, and health. Canadian Psychology, 49(3), 182-185. https://doi.org/10.1037/a0012801.

Deci, E, L., \& Ryan, R, M. (2012). Motivation, personality, and development within embedded social contexts: An overview of self-determination theory. In R. M. Ryan (Ed.), The Oxford handbook of human motivation (pp. 85-107). Oxford University Press Inc.

Doménech-Betoret, F., Abellán-Roselló, L., \& Gómez-Artiga, A. (2017). Self-efficacy, satisfaction, and academic achievement: The mediator role of students' expectancy-value beliefs. Frontiers in Psychology, 8, online journal. https://doi.org/10.3389/fpsyg.2017.01193.

Eccles, J, S. (1983). Expectancies, values, and academic behaviors. In J. T. Spence (Ed.), Achievement and achievement motives (pp. 75-146). Freeman.

Eccles, J, S. (2005). Subjective task values and the Eccles et al. model of achievement related choices. In A. J. Elliot \& C. S. Dweck (Eds.), Handbook of competence and motivation (pp. 105-121). Guilford.

Eccles, J, S., Wigfield, A., \& Schiefele, U. (1998). Motivation to succeed. In W. Damon \& N. Eisenberg (Eds.), Social, emotional, and personality development (pp. 1017-1095). Handbook of child psychology. John Wiley \& Sons Inc.

Elola, I., \& Oskoz, A. (2010). A social constructivist approach to foreign language writing in online environments. AAUSC 2010: Critical and Intercultural Theory and Language Pedagogy, 181.

Fornell, C., \& Larcker, D. F. (1981). Evaluating structural equation models with unobservable variables and measurement error. JMR, Journal of Marketing Research, 18, 39-50. https://doi.org/10.1177/ 002224378101800104.

Garnjost, P., \& Lawter, L. (2019). Undergraduates' satisfaction and perceptions of learning outcomes across teacher-and learner-focused pedagogies. The International Journal of Management Education, 17(2), 267-275. https://doi.org/10.1016/j.ijme.2019.03.004.

George, D., \& Mallery, M. (2010). SPSS for Windows step by step: a simple guide and reference, 17.0 update (10th ed.). Allyn \& Bacon.

Hair, J., Black, W., Babin, B., \& Anderson, R. (2010). Multivariate data analysis (7th ed.). Prentice-Hall, Inc.

Hopkins, J. E. (2010). Distance language learners' perceptions of assessed, student-led speaking tasks via a synchronous audiographic conferencing tool. Innovation in Language Learning and Teaching, 4(3), 235258. https://doi.org/10.1080/17501229.2010.513446.

Huffman, S, R. (2010). Using mobile technologies for synchronous CMC to develop L2 oral proficiency. Center for Communication Excellence Proceedings and Presentations. 2. https://lib.dr.iastate.edu/ communicationexcellence_conf/2 
Jung, I., Choi, S., Lim, C., \& Leem, J. (2002). Effects of different types of interaction on learning achievement, satisfaction and participation in web-based instruction. Innovations in Education and Teaching International, 39(2), 153-162. https://doi.org/10.1080/14703290252934603.

Kato, F., Spring, R., \& Mori, C. (2016). Mutually beneficial foreign language learning: Creating meaningful interactions through video-synchronous computer-mediated communication. Foreign Language Annals, 49(2), 355-366. https://doi.org/10.1111/flan.12195.

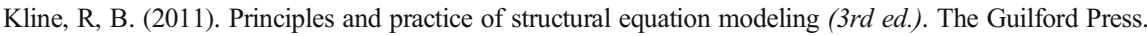

Lederman, D. (2020). What worked this spring? Well-designed and -delivered courses. Inside Higher Ed. online article retrieved from https://bit.ly/3eo25Q1

Luyten, H., \& Bazo, M. (2019). Transformational leadership, professional learning communities, teacher learning and learner centred teaching practices; evidence on their interrelations in Mozambican primary education. Studies in Educational Evaluation, 60, 14-31. https://doi.org/10.1016/j.stueduc.2018.11.002.

Moore, M, G., \& Kearsley, G. (1996). Distance education: A systems view. Wadsworth Publishing Company.

Mupinga, D. M., Nora, R. T., \& Yaw, D. C. (2006). The learning styles, expectations, and needs of online students. College Teaching, 54(1), 18-189. https://doi.org/10.3200/CTCH.54.1.185-189.

Nortvig, A. M., Petersen, A. K., \& Balle, S. H. (2018). A literature review of the factors influencing e-learning and blended learning in relation to learning outcome, student satisfaction and engagement. The Electronic Journal of e-Learning, 16(1), 46-55 www.ejel.org.

Payne, J. S. (2020). Developing L2 productive language skills online and the strategic use of instructional tools. Foreign Language Annals, 53, 243-249. Advance online publication. https://doi.org/10.1111/flan. 12457.

Payne, J., \& Whitney, P. (2002). Developing L2 Oral proficiency through synchronous CMC: Output, working memory, and Interlanguage development. CALICO Journal, 20(1), 7-32. https://doi.org/10. 1558/cj.v20i1.7-32.

Pozón-López, I., Higueras-Castillo, E., Muñoz-Leiva, F., \& Liébana-Cabanillas, F. J. (2020). Perceived user satisfaction and intention to use massive open online courses (MOOCs). Journal of Computing in Higher Education, 1-36. https://doi.org/10.1007/s12528-020-09257-9.

QSR International (1999). NVivo Qualitative Data Analysis Software [Software]. Available from https:// www.qsrinternational.com/

Rao, P. S. (2019). The importance of speaking skills in English classrooms. Alford Council of International English \& Literature Journal (ACIELJ), 2(2), 6-18.

Rapanta, C., Botturi, L., Goodyear, P., Guàrdia, L., \& Koole, M. (2020). Online university teaching during and after the Covid-19 crisis: Refocusing teacher presence and learning activity. Postdigital Science and Education, 1-23. https://doi.org/10.1007/s42438-020-00155-y.

Ryan, R. M. (1982). Control and information in the intrapersonal sphere: An extension of cognitive evaluation theory. Journal of Personality and Social Psychology, 43(3), 450-461. https://doi.org/10.1037/00223514.43.3.450.

Ryan, R. M., \& Deci, E. L. (2000). Self-determination theory and the facilitation of intrinsic motivation, social development, and well-being. The American Psychologist, 55(1), 68-78. https://doi.org/10.1037/0003066X.55.1.68.

Ryan, R. M., \& Deci, E. L. (2020). Intrinsic and extrinsic motivation from a self-determination theory perspective: Definitions, theory, practices, and future directions. Contemporary Educational Psychology, 101860. Advance online publication. https://doi.org/10.1016/j.cedpsych.2020.101860.

Saeed, M. A., \& Ghazali, K. (2017). Asynchronous group review of EFL writing: Interactions and text revisions. Language Learning \& Technology, 21(2), 200-226. http://hdl.handle.net/10125/44618.

Sanjay, G., \& Narayana, T. (2020). Teaching speaking skills through motivational strategies. Research Journal of English (RJOE), 5(5), 37-49 https://www.rjoe.org.in/Files/v5i2/4.RJOE-G.SANJAY_37-49. pdf.

Shahijan, M. K., Rezaei, S., \& Amin, M. (2016). International students' course satisfaction and continuance behavioral intention higher education setting: An empirical assessment in Malaysia. Asia Pacific Education Review, 17(1), 41-62. https://doi.org/10.1007/s12564-015-9410-9.

Shire, S. Y., Worthman, L. B., Shih, W., \& Kasari, C. (2020). Comparison of face-to-face and remote support for interventionists learning to deliver JASPER intervention with children who have autism. Journal of Behavioral Education, 29, 317-338. https://doi.org/10.1007/s10864-020-09376-4.

Song, Z. X., Cheung, M. F., \& Prud'Homme, S. (2017). Theoretical frameworks and research methods in the study of MOOC/e-learning behaviors: A theoretical and empirical review. In W. Ma, C. K. Chan, K. Tong, H. Fung, \& C. Fong (Eds.), New Ecology for Education - Communication X Learning (pp. 4765). Springer. https://doi.org/10.1007/978-981-10-4346-8_5. 
Spring, R., Kato, F., \& Mori, C. (2019). Factors associated with improvement in oral fluency when using video-synchronous mediated communication with native speakers. Foreign Language Annals, 52(1), 87100. https://doi.org/10.1111/flan.12381.

Stewart, G. L., Manges, K. A., \& Ward, M. M. (2015). Empowering sustained patient safety. Journal of Nursing Care Quality, 30(3), 240-246. https://doi.org/10.1097/NCQ.0000000000000103.

Such, B. (2019). Scaffolding English language learners for online collaborative writing activities. Interactive Learning Environments, 1-9. https://doi.org/10.1080/10494820.2019.1579233.

Thurmond, V. A., Wambach, K., Connors, H. R., \& Frey, B. B. (2002). Evaluation of student satisfaction: Determining the impact of a web-based environment by controlling for student characteristics. American Journal of Distance Education, 16(3), 169-190. https://doi.org/10.1207/S15389286AJDE1603_4.

Wigfield, A., \& Cambria, J. (2010). Expectancy-value theory: Retrospective and prospective. Advances in motivation and achievement, 16(part a), 35-70. https://oi.org/10.1108/S0749-7423(2010)000016A005.

Wigfield, A., \& Eccles, J. S. (2000). Expectancy-value theory of achievement motivation. Contemporary educational psychology, 25(1), 68-81. https://doi.org/10.1006/ceps.1999.1015.

Wilson, K. (2016). Smart choice (2nd ed.). Oxford University Press.

Yanguas, I. (2020). L1 vs L2 synchronous text-based interaction in computer-mediated L2 writing. System, 88, 102169. https://doi.org/10.1016/j.system.2019.102169.

Yeh, S. W., Lo, J. J., \& Huang, J. J. (2011). Scaffolding collaborative technical writing with procedural facilitation and synchronous discussion. International Journal of Computer-Supported Collaborative Learning, 6(3), 397-419. https://doi.org/10.1007/s11412-011-9117-9.

Zimmerman, B. J. (2002). Becoming a self-regulated learner: An overview. Theory into Practice, 41(2), 64 70. https://doi.org/10.1207/s15430421tip4102_2.

Publisher's note Springer Nature remains neutral with regard to jurisdictional claims in published maps and institutional affiliations.

\section{Affiliations}

\section{Daniel Bailey $^{1} \cdot$ Norah Almusharraf $^{2} \cdot$ Ryan Hatcher $^{3}$}

1 English Language and Literature Department, Konkuk University’s Glocal Campus, Chungju, South Korea

2 Applied Linguistics Department, College of Humanities, Prince Sultan University, Riyadh, Saudi Arabia

3 Hannam University, Daejeon, South Korea 